\title{
OPTIMIZATION OF SOFTWARE REQUIREMENT PROCESS: AN INTEGRATED CONCEPTUAL MODEL OF LEAN SIX SIGMA AND REQUIREMENT PLANNING
}

\author{
NARISHAH MOHAMED SALLEH* ${ }^{*}$ PUTERI N. E. NOHUDDIN" \\ Institute Visual Informatics, UKM Bangi, 4300 Selangor, Malaysia \\ *E-mail: narishah2@gmail.com (Corresponding author) \\ \#E-mail: puteri@ivi.ukm.my (Main author)
}

\begin{abstract}
Providing quality requirements in Software Engineering is vital to ensure the product developed is able to deploy and function to meet the operational objectives. Software Requirement Engineering is the most complex process because it involves the integration of human, logics and process. Extracting or capturing what customers need and want is called Requirement Elicitation (RE) and it is the most crucial process in requirement engineering. If handled poorly, the cost of the failures would be very expensive. Most of the software projects that failed were due to poor requirements which occurred at RE phase. Thus, enhancing and optimizing the RE methods have been subject to a long research debate to ensure quality requirements are captured. Recently, Lean Six Sigma (LSS) had emerged as part of a continuous improvement in Software Development Life Cycles (SDLC). LSS is known for a systematic and structure business improvement successfully deployed in many fields of industry that contributes a significant gain not only in quality of products and services but also in operational costs and delivery. The objective of the research is to develop an integrated conceptual framework of LSS principles with Software Requirement Engineering methodology to optimize RE process. The article will produce conceptual framework as the comprehensive guidelines to capture quality software requirements.
\end{abstract}

Keywords: Requirement Elicitation, Requirement Engineering, Lean Six Sigma, Requirement Elicitation Technique, DMAIC

\section{Introduction}

In the current Digital Age, the needs for Information Technology applications become a necessity to support operational efficiency. Software requirement is the most critical phase in the entire development life cycle. The most important task in this phase is RE with the primary objective is to explore and to discover the scope of software, to understand the customer concerns and to realize the company's objective. Without an accurate understanding of stakeholders' specifications, the tendency of projects to fail is of high degree. According to [1], more than $50 \%$ of the software project failures are related to poor requirements which occurred at RE phase. A study done by Standish Report in 2014 revealed that the highest requirement challenges were Incomplete Requirement (13\%) and Lack of User Involvement (12.4\%).

$\mathrm{RE}$ techniques were discussed in many literatures to enhance the elicitation process, for example; selecting the right techniques in different situations, comparison of the effectiveness of RE techniques and many more. Common RE techniques are Interviews, Rapid Prototyping, Surveys, Focus Groups, discussions and brainstorming to capture the end users' requirements [2-5]. However, a single RE technique could not resolve all the RE challenges because each situation is unique and requires different $\mathrm{RE}$ techniques. [3, 5] suggested a combination of elicitation techniques to solve different types of requirement challenges.

The situation becomes very critical if end users are not able to describe the actual requirement during the gathering process. In most of the cases, users could not identify the relationship of the problems facing the actual needs to resolve. Combination of RE techniques would be an exhaustive elicitation process which may cause projects to be overrun in delivery and cost. In this type of scenario, the requirement gathering process should start by understanding the

Open Acces statement. This is an open-access article distributed under the terms of the Creative Commons AttributionNonCommercial 4.0 International License (https://creativecommons.org/licenses/by-nc/4.0/), which permits unrestricted use, distribution, and reproduction in any medium for non-commercial purposes, provided the original author and source are credited, a link to the CC License is provided, and changes - if any - are indicated. 


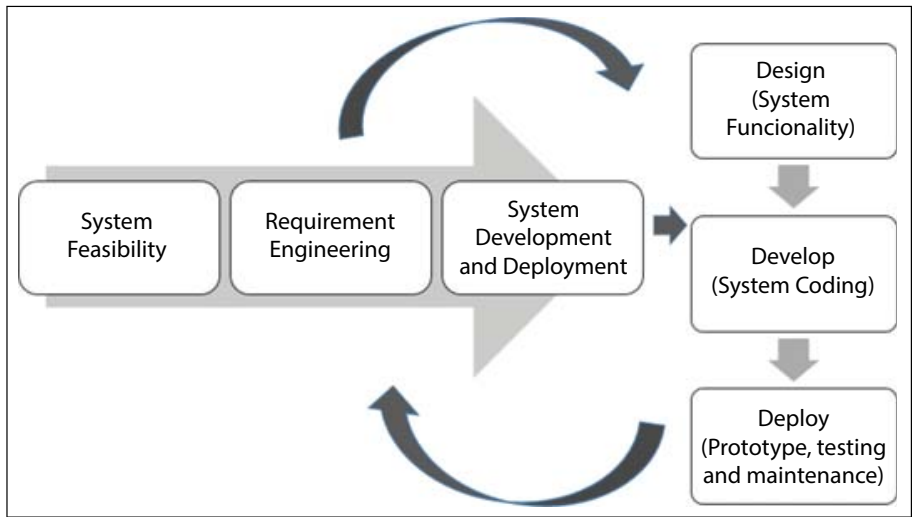

Fig. 1. Requirement engineering and software development activities [9]

problem situations before capturing the actual requirements from clients. Thus, an alternative approach is needed to explore such scenarios with a combination of multiple RE techniques. The enhanced methodology should explore an end to end process in the entire value chain.

LSS is a new emerging method in software development life cycle and it is well known as a strategic business improvement methodology applied using DMAIC (define, measure, analyze, improve, control) approach as the conjoint continuous improvement framework [6-8]. The entire approach of DMAIC framework is to explore the problems, to understand the baseline and to propose optimized solutions for the organization's improvement. DMAIC is equipped with many different types of tools and techniques along the phases, defining which tools at what steps are crucial to assist in software requirement process. Those techniques and tools will assist in exploring and visualizing the problems comprehensively. Most of the research in software engineering is applying the whole DMAIC method to replace the entire SDLC process with the assumptions that the stakeholders knows about the requirements needed. High uncertainties and complexity of software requirements were not discussed in the previous researches which required holistic approach in selecting and evaluating the right tools and techniques of the DMAIC approach.

The objective of the research is to develop an integrated conceptual model which combines LSS principle and method with requirement engineering life cycle to optimize the RE process. The conceptual model will emphasize and focus more on the initial stage of the DMAIC framework particularly at the Define and Measure Phase. This is because the two phases are highly correlated to RE process in general.
The outcome of the research is to propose guidelines of what Tools and Techniques should be taken to improve the RE process in order to capture quality requirements in a comprehensive and holistic approach. The rest of the paper is organized as follows. Section 2 discusses the background of RE techniques and LSS methodologies. Section 3 describes in detail how the proposed framework will be constructed and how it will be conducted in the case study. Section 4 will discuss the expected outcomes that derived from the proposed framework.

\section{Literature review}

\subsection{Requirement Engineering life cycle}

The primary objective of Requirement Engineering is to capture the right requirements from the end users about how the systems should function and ultimately to improve the efficiency of the organization's workflow. More effective methods devoted during requirement activities guaranteed a quality system which is not only cost effective but increases customer satisfaction. Figure 1 represents the importance connection between requirement engineering and software development life cycle:

In the early stage, requirement has a significant relation with system feasibility to explore and to understand how the system functioned. In system design and development phase, requirements are used as decision making or rules to navigate actions. Lastly, in deployment phase, it is to confirm and to validate the system functionality. According to [10], requirement engineering procedures can be segregated into five main phases; elicitation, analysis, specification, validation and management as shown in Fig. 2:

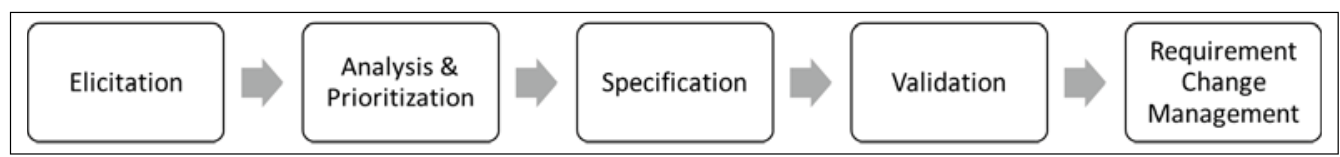

Fig. 2. Phases in Requirement Engineering 
Table 1. RE techniques based on situational characteristic

\begin{tabular}{|c|c|c|}
\hline Category & RE technique & Most recommended situation \\
\hline \multirow[t]{3}{*}{ Traditional } & Surveys, questionnaires & Preliminary background of the case study \\
\hline & $\begin{array}{l}\text { Interviews, Task Analysis, } \\
\text { Domain Analysis }\end{array}$ & $\begin{array}{l}\text { Experienced and expert, high competent end } \\
\text { users }\end{array}$ \\
\hline & Introspection & $\begin{array}{l}\text { High experience and high skills of analyst at } \\
\text { the specific domain of knowledge }\end{array}$ \\
\hline \multirow[t]{3}{*}{ Cognitive } & Card Sorting & Simple domain knowledge \\
\hline & Laddering & Single stakeholders \\
\hline & Repertory Grid & Simple requirements \\
\hline \multirow[t]{3}{*}{ Collaborative } & $\begin{array}{l}\text { Focus Group, } \\
\text { Brainstorming }\end{array}$ & Multiple stakeholders \\
\hline & Requirement Workshop & $\begin{array}{l}\text { Big projects, complex and comprehensive } \\
\text { requirements }\end{array}$ \\
\hline & Prototyping & Highly participative end users \\
\hline \multirow[t]{2}{*}{ Contextual } & Ethnography & Problems were unknown \\
\hline & Observation & $\begin{array}{l}\text { Users do not know how to articulate the } \\
\text { process, lack of users' participation }\end{array}$ \\
\hline
\end{tabular}

The phases were performed in iteration mode. Elicitation is the most important step to discover the needs from the stakeholders. It is about scoping the challenges faced by end users. It is the process to capture how the new system will be able to perform as per the customer needs to improve the operational difficulties. Analysis is the process of analyzing all non-functional and functional requirements. It is also a phase to understand how those requirements met the objective of the organization. This will be completed once the requirement specifications are validated in the requirement validation process. Managing the requirement changes is also highly important to ensure projects delivery is on track and costs will not overrun. The tasks at RE required extensive activities from analysts or requirement engineers to make the greatest possible amount of tacit knowledge explicit, synthesize the disperse knowledge and reconcile the diverse beliefs and necessities of the domain specialists. Lack of participation users, incomplete organization work flow or documentations, the confused views from end users and others are the challenges faced during RE processes. These will lead to high failure rate and an increase of bugs rework. One of the important solutions to optimize the elicitation activities is RE technique.

RE techniques are the process to capture the needs and wants of customers. Combination of RE techniques based on situational background are recommended by most of the literatures. This is also confirmed by [2,3] who evaluated different RE techniques to be applied in different situations. [12, 13] categorized the elicitation techniques into Traditional, Collaborative, Cognitive and Observational, which are summarized in Table 1. Each group has its own approach to be applied during RE process.

In reality, the selection of RE techniques is not as easy as tabulated because it requires proper preparation before the process starts. There will be high consumption rates of man hours to be spent during the gathering process with no guarantee of success. This is supported by [14], who discovered lack of interest on the part of users to participate. Thus, exploring a holistic problem solving approach is vital to ensure business improvement. LSS is an emerging methodology in software development cycle which involved project by project approach of implementation.

\subsection{Lean Six Sigma: Principle and method}

Lean Six Sigma (LSS) is a methodology which derived from Six Sigma and Lean Management principle [15]. LSS helps to identify the cause of a problem and implement the solution based on facts, rather than assumptions. It is the integrated methodology with a systematic approach to improve organizational performance by removing process wastes and reducing variation through diagnosis and analysis capabilities of Six Sigma. The integration of lean and Six Sigma allows employees to have greater autonomy in relation to operational processes making the process of continuous improvement more solid. It also allows the organization to obtain enhanced performance through the application of tools that contribute to the continuous improvement of processes [16]. Table 2 summarizes the LSS principles. 
Table 2. LSS principle [17]

\begin{tabular}{|c|c|c|}
\hline & Principle & Description \\
\hline 1 & Focus on Customers & $\begin{array}{l}\text { It is a principle of creating values to the customer. Any processes that } \\
\text { do not benefit customers will be considered as a waste [18] }\end{array}$ \\
\hline 2 & Value Stream & $\begin{array}{l}\text { Identifying and understanding how the works get done through value } \\
\text { stream mapping is crucial to visualize the current process before new } \\
\text { solution is proposed }\end{array}$ \\
\hline 3 & $\begin{array}{l}\text { Remove non-value added } \\
\text { steps and waste }\end{array}$ & $\begin{array}{l}\text { From Value Stream analysis, all non-value added tasks and steps } \\
\text { should be eliminated from the process to ensure the smoothness of the } \\
\text { flow [19] }\end{array}$ \\
\hline 4 & $\begin{array}{l}\text { Manage, improve and smooth } \\
\text { the process flow }\end{array}$ & $\begin{array}{l}\text { Lean principle itself is about managing a smooth flow not only in } \\
\text { operations, but also in the information and the material flow where } \\
\text { complexity should be managed and improved }\end{array}$ \\
\hline 5 & $\begin{array}{l}\text { Manage by fact and reduce } \\
\text { variation }\end{array}$ & $\begin{array}{l}\text { LSS emphasizes that problems are based on solid evidence and } \\
\text { baseline data where process improvement is derived from a structured } \\
\text { statistical analysis [20] }\end{array}$ \\
\hline 6 & $\begin{array}{l}\text { Undertake improvement } \\
\text { activity in a systematic way }\end{array}$ & $\begin{array}{l}\text { LSS followed systematic and proven statistical tools which are applied } \\
\text { to ensure business efficiency and customers' satisfaction }\end{array}$ \\
\hline 7 & $\begin{array}{l}\text { Involve and equip the people } \\
\text { in the process }\end{array}$ & $\begin{array}{l}\text { Resources is the most important element in LSS principle where } \\
\text { increasing values through respect, empowerment and growth of } \\
\text { learning are vital to improve collaboration and teamwork }\end{array}$ \\
\hline
\end{tabular}

Many Researchers across the world have projected various frameworks and/or models to address various implementation issues of Lean, Six Sigma and LSS. The implementation of the integrated lean sigma framework presents an impressive improvement in chief metrics and considerable financial savings to be generated by the organization [21,22].

Figure 3 is the DMAIC framework which was proposed by [23] to replace IT SDLC project management with specific tools assigned at each sub-task for each phase.

Each phase has its standard tollgate checklists per LSS International Standard 2010 where it defines pro- ject deliverables. Defining is the first phase to investigate the objective of the project, to identify the stakeholders, to understand and to explore what is business functionalities. The project leads will investigate high level map of current process to understand the overview of the flow [24]. The problem statement and objective must be Specific, Measureable, Achievable, Realistic and Time-bound (S-M-A-R-T).

In LSS, Voice of Customer (VOC) is one of the common tools used to capture customers' requirement. The elicitation technique is done through surveys, market research, benchmark analysis, focus group discussion and interviews. Most important steps of the

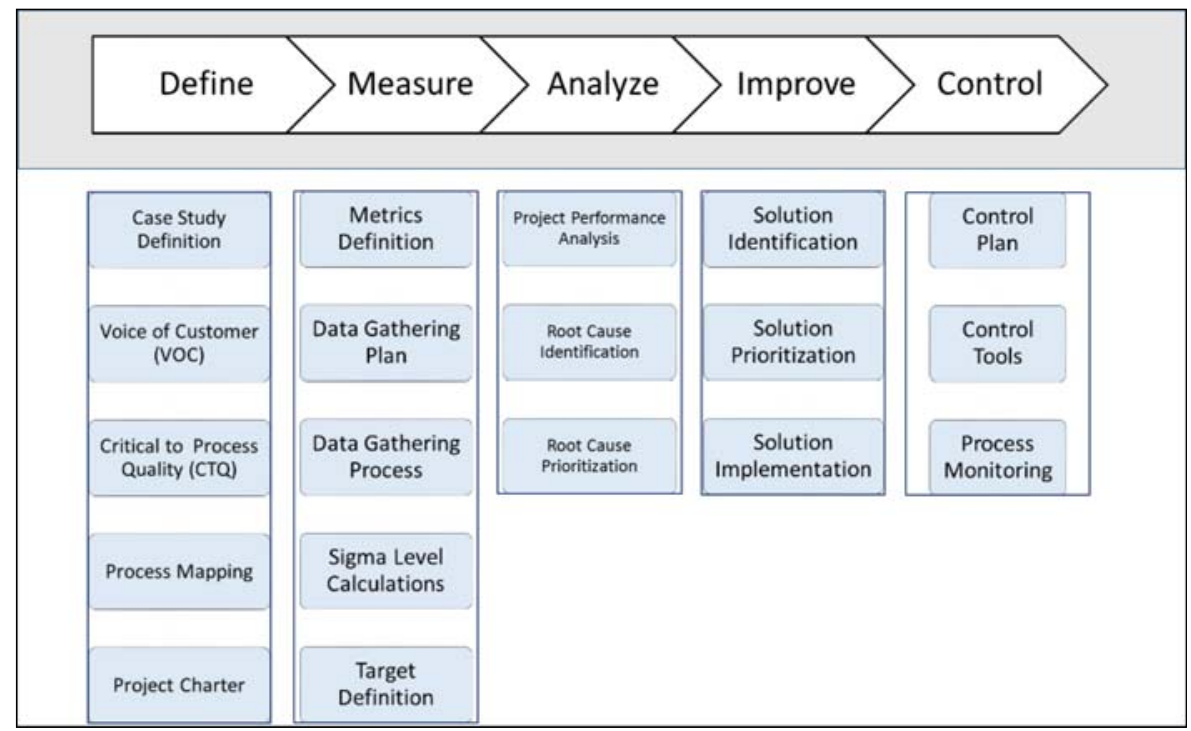

Fig. 3. DMAIC framework [23] 
LSS project aim to detect the Critical-to-Quality process factors (CTQs), which derived from VOC tool. Drill-down Tree template is one the effective tools to assist analysts to extract the customers' wants and lastly translated into voice of process or the voice of business that contributes to customer needs. In fact, "Focus on Customers" is LSS first principle, where any process that does not contribute to customer's requirement is considered non-value added. Other significant DMAIC tool is process mapping, which generated from lists of CTQs that visualize roles and tasks. Lastly, the formation of Project Charter, which contains the most significant objectives and project deliverable metrics [25]. Project charter is the main motivation for why projects should be pursued.

Measure Phase is to understand current baseline performance of key variables. [26] explained measure phase is the phase for data collection development to determine issues and shortfalls. Analyze phase is the stage to evaluate the process variations, to perform root cause analysis and prioritize opportunity of improvements. The recommended tools at this stage are Ishikawa Diagram, Five Why's exercise activities, statistical tools analysis to understand the baseline and to explore opportunities for improvement. Improve Phase is the phase for team to evaluate or to develop alternative solutions. Last phase is to develop the monitoring plan. Recommended tools are effective communication, long term solutions such as web based monitoring systems or control charts, awareness and others [27].

\subsection{Application of LSS principle and method in Requirement Engineering}

Revised LSS framework had evolved over the years to promote continuous improvement at different DMAIC phases. Reference [19] proposed enhancement of SIPOC tools to explore the relationship of customer wants and customer needs to improve project management costs. Reference [8] enhanced typical SIPOC definition into software perspective which laid out as User Requirement (Supplier), Activities (Input), Validation (Process), Tools (Output) and Customer Agreement / Contract (Customer).

Kano-LSS (KLSS) model is used to identify the exact requirements for the software project from the customer's perspective [24]. KLSS helps to categorize the requirements based on the nature of the defect, to eliminate the requirements of non-value processes and to implement the main functionality to meet the expectations of the customers. There are other tools that can be applied, for example "Map As-Is-Process", where current process mapping using Swim Lane Diagram can be performed to understand current process work flow. From Swim Lane Diagram or Detail process mapping, Waste Analysis can be performed to identify which factors are classified as value essential and non-value added [28].

The method of choice to uncover causes and effect known as Transfer Functions or Linear Mathematical Equation Model is also one of the significant tools used to explore implicit requirements. The change metrics are presented based on Goal Quality Model (GQM) and the requirement changes are classified according to their effect in project quality [29]. This linear mathematical equation model is vital to understand the relationship of input variables towards the output metrics.

Introduction of VOC at a very early phase as shown in Fig. 3 will lead to poor requirement because of below possible scenarios: a) Users are not sure of the organization objective. b) Multiple stakeholders may have diverging interests and perceptions that lead to conflicting and inconsistent information. c) Frequent changes of stakeholders may lead to conflicting and incomplete information.

DMAIC has been applied in manufacturing process for so many years with multiple type of tools at each phase depending on the objective of the projects which mainly related to cost and productivity improvement. There are multiple ways to apply the tools at different case and scenario. However, none of the research confirms which tools or framework are able to minimize the "Incomplete Requirement" and "lack of users involvement" requirement challenges. This research proposes enhanced DMAIC framework that will combine the attribute of Transfer Function model with respective DMAIC tools at Define and Measure phase. The combination and arrangement of SIPOC, Process Mapping, VOC and Transfer Function models are able to draw a significant conclusion whether a quality software requirement could be established. The new enhanced DMAIC framework known as DMAICTF-REI (DMAIC - Transfer Function for Requirement Engineering Improvement) is proposed.

\section{Developing a conceptual improvement model to integrate DMAIC and Requirement Engineering process}

There are two main categories in requirement engineering which are identified as [30]:

a) Requirement Gathering or Requirement Planning,

b) Requirement Implementation.

Requirement Planning is the significant phase to identify the end users' pain points, to capture the requirement, to perform requirement analysis and to prioritize which type of requirements were important and urgent before design and development were initi- 


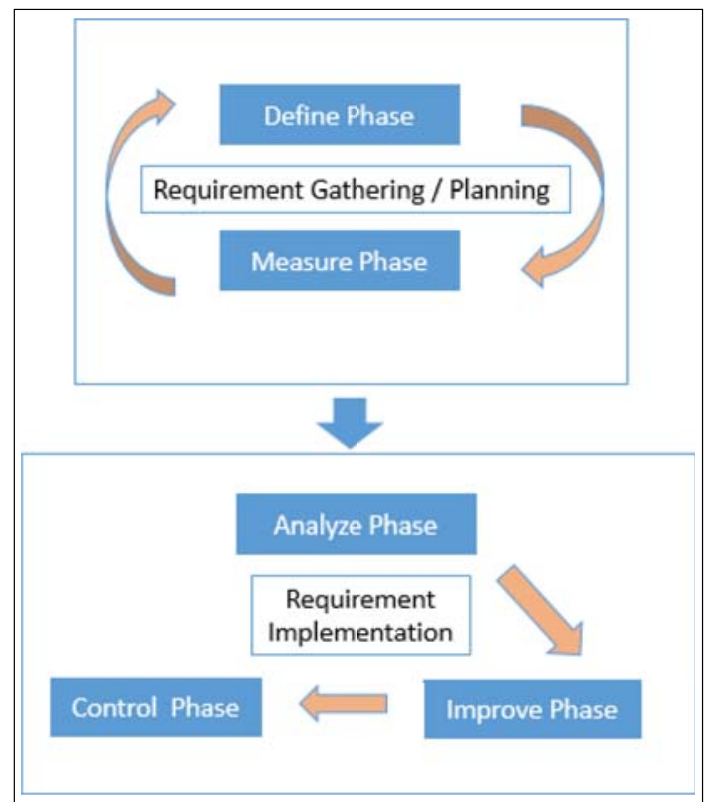

Fig. 4. The Conceptual Improvement Model (DMAIC in Requirement Engineering)

ated. Requirement Implementation is the development, deployment and maintenance phase of the system or software. This is basically the process to confirm the completeness and to validate the correctness of the requirement.

Figure 4 illustrates the conceptual diagram of LSS and Requirement Engineering improvement model.

The proposed development model will resolve the requirement planning process. It is to address the requirement engineering main challenges which are "incomplete requirement" and "lack of user participation". The conceptual model is derived from basic foundation of requirement engineering model based on the two main categories explained earlier in Section 3.

DMAIC processes are divided into two main categories of requirement engineering where Define and Measure phase is a strategic cycle, the backbone of the requirement gathering and planning activities. While Analyze, Improve and Control Phase fall in the implementation process to ensure sustainability, but will not be discussed in this paper. Detail task and tools at Define and Measure phase will be elaborated and evaluated to support the improvement model to minimize the impact of incomplete requirement and lack of user support. Each model composes of distinct steps and tools but the focus of the research is the requirement planning model which will be described in Section 3.1.

\subsection{Tools, techniques and activities in Requirement Planning model}

Strategic or planning model is composed of several critical steps as analyzed in Section 2. It is to align the applicability of a theory in accordance with [31], which is to build the understanding and confirming the claimable theory. Figure 5 summarized the proposed activities in requirement planning. Define phase is composed of seven activities:

- Identify the problems

- Overall process view

- Describe and visualize current process details

- Establish current transfer function

- Eliciting customer needs

- Translating those needs into critical input variables

- Development of requirement documentation (Project Charter)

At the same time, measure phase consists of six activities:

- Waste analysis

- Future process mapping

- Proposed new transfer function

- Throw-away prototyping for requirement validation

- Establishing of software requirement specification

- Risk management

There are several tools which will be proposed at each activity as part of the guidance and practicality to be evaluated in any type of requirement engineering study. Figure 5 adopted the DMAIC toolbox which was described in Fig. 3 in Section 2.2 with different arrangement to support the situational RE challenges with the assumption of "Unknown" requirement. The recommended tools will be explained in Section 3.2. 


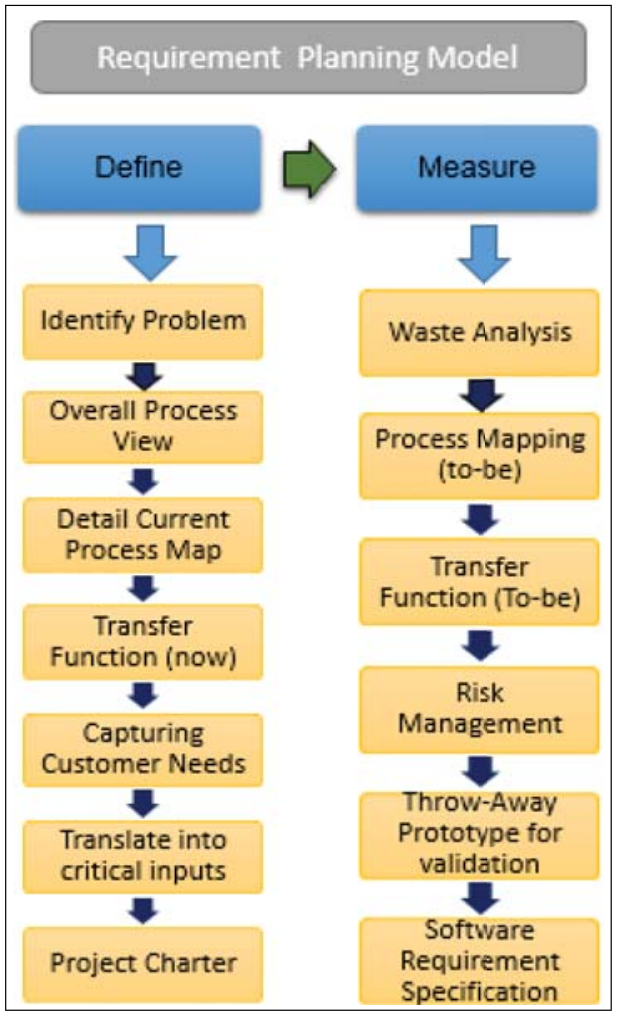

Fig. 5. Overview of define and measure phase model

\subsection{Define and measure phase model}

The application of the quality tool at each activity will explore the detail requirement to a greater ex- tent. Table 3 outlines the recommended tools to be applied at each activity. The introduction of transfer function techniques in the model will assist in predicting the optimized variables for overview requirements.

Why proposed conceptual model is able to minimize the impact of incomplete requirement? This is because the application of SIPOC in the early stage will capture a comprehensive diagram to explore all the components in the supply chain of the process. The workflow diagram in software development context, starts with: 1) who supplies the information? 2) What kind of input variables are needed to produce the critical output responses? 3) What are the typical steps to process all the important input variables? 4) Who needs to receive such information and 5) what type of outputs will be produced by the system?

This leads to an easy step to construct the process mapping with the information derived from SIPOC which identifies who the stakeholders are and respective roles in comprehensive and structured procedures. Constructing a process mapping based on verbal discussion with the end users will be leading to a very long process if the users were not very familiar with the workflow. It may resolve at the specific area only which looks like "a piecemeal" solution.

This is supported with the derivation of transfer function model that explains the correlation of input and output implicitly and explicitly.

Table 3. Recommended tools and technique at requirement DMAIC model

\begin{tabular}{|c|c|c|c|}
\hline Phase & Activities & Tool \& Technique & Description \\
\hline \multirow[t]{7}{*}{ Define } & Identify Problem & Focus Group Discussion & $\begin{array}{l}\text { Discussion is appropriate to understand the pain points } \\
\text { from the end users. }\end{array}$ \\
\hline & Establish Process overview & SIPOC & $\begin{array}{l}\text { SIPOC is able to identify affected stakeholders, main } \\
\text { functionality detail process, rules and regulations and } \\
\text { other relevance components. }\end{array}$ \\
\hline & Detail Process & Process Mapping Tools & $\begin{array}{l}\text { Detail Flow Diagram or Business Process Model is } \\
\text { transformed into detail mapping to describe the roles } \\
\text { and responsibility of each stakeholders, also the view of } \\
\text { the relationship of the input and the output. }\end{array}$ \\
\hline & $\begin{array}{l}\text { Establish Current Transfer } \\
\text { Function }\end{array}$ & $\begin{array}{l}\text { Linear Mathematical } \\
\text { Model }\end{array}$ & $\begin{array}{l}\text { The proposed equation is to understand the current } \\
\text { states of input variables in correlation with output } \\
\text { parameters. }\end{array}$ \\
\hline & $\begin{array}{l}\text { Eliciting Customer } \\
\text { Requirement }\end{array}$ & VOC & $\begin{array}{l}\text { VOC templates will extract customer needs with three } \\
\text { main objectives: 1) What are the needs? 2) Why needs } \\
\text { are important? 3) How to deliver the needs? }\end{array}$ \\
\hline & $\begin{array}{l}\text { Transfer Needs into } \\
\text { Critical to Quality Inputs }\end{array}$ & CTQ Tree Diagram & $\begin{array}{l}\text { CTQ Tree diagram is able to transform the customer's } \\
\text { expectation into critical business process parameters that } \\
\text { could be developed in future. }\end{array}$ \\
\hline & Establish Project Charter & $\begin{array}{l}\text { Six Sigma Project Charter } \\
\text { Template }\end{array}$ & $\begin{array}{l}\text { This is a business template where senior management } \\
\text { has to acknowledge whether the project should be } \\
\text { pursued or not }\end{array}$ \\
\hline
\end{tabular}


Table 3. (cont'd)

\begin{tabular}{|c|c|c|c|}
\hline Phase & Activities & Tool \& Technique & Description \\
\hline \multirow[t]{6}{*}{ Measure } & Waste Analysis & Analysis Tool & $\begin{array}{l}\text { This is to identify which steps of the process that were } \\
\text { not value added to the customers' expectation could } \\
\text { either be removed from the process or could be replaced } \\
\text { with code algorithm to speed up the task. }\end{array}$ \\
\hline & Future Process Mapping & Process Mapping Tools & $\begin{array}{l}\text { This tool develops new business process model using } \\
\text { BPM or DFD }\end{array}$ \\
\hline & Transfer Function (To-be) & $\begin{array}{l}\text { Linear Mathematical } \\
\text { Equation }\end{array}$ & $\begin{array}{l}\text { This equation establishes new linear equations of } \\
\text { significant parameters }\end{array}$ \\
\hline & $\begin{array}{l}\text { Validation Using throw- } \\
\text { way Prototyping Method }\end{array}$ & $\begin{array}{l}\text { Software Application: } \\
\text { Sketch or Dreamweaver }\end{array}$ & $\begin{array}{l}\text { Tool for sketching or designing proposed structure and } \\
\text { layout of the system applications for validation and } \\
\text { confirmation from stakeholders. }\end{array}$ \\
\hline & Risk Management & $\begin{array}{l}\text { Risk Management } \\
\text { Analysis }\end{array}$ & $\begin{array}{l}\text { The process establishes risk analysis using Severe, } \\
\text { Occurrence and Detect capability tools. }\end{array}$ \\
\hline & $\begin{array}{l}\text { Software Requirement } \\
\text { Specification (SRS) }\end{array}$ & SRS Template & $\begin{array}{l}\text { It is part of Requirement management changes in case } \\
\text { changes would occur in the future. }\end{array}$ \\
\hline
\end{tabular}

\subsection{Expected benefits}

The likely benefits of the proposed approach are:

- The steps proposed are very comprehensive, which covered the basic area of the relationship of the input components to the expected outputs of the software requirement.

- The tools recommended in conceptual models could enable the analyst to predict the subsequent relevance questions from the conversational activities with end users.

- The waste analysis tool applied to analyze the steps in process mapping is the complementary benefit of removing non-value-added activities from the organization workflows

- The introduction of linear mathematical transfer function is able to extract the implicit knowledge from the end users from sub functionality of the input and output correlation variables.

\subsection{Validation of the model}

Validation of the model can be performed at many different levels of stakeholders from as lower as admin levels to managers' level and can be done within a group or independently. It also could be tested at any type of industry from many different domains of knowledge, for example Human Resource System, Financial Management, Distributed Management or Supply Chain Management, Logistic System, Health Management System, maintenance and others. It could be validated face to face or via remote discussion. It can be studied either in simple projects or large scale and complex processes with multiple distributed geographical locations.

\section{Conclusion and future work}

The significance of the study is to propose a new framework to assist business analysts to capture the right requirement which is extracted with the LSS quality tools that comprehensively look at end to end value chain. This process is very significant not only to improve overall company costs and revenue but also to look at the alternative in resolving the incomplete requirement issues in the software industries. This proposed framework could be enhanced to cater for a complex software requirement in preparing the small medium companies for Industrial 4.0 revolution.

\section{References}

[1] Khan M. N. A., Khalid M., ul Haq S. (2013), Review of requirements management issues in software development. Int. J. Mod. Educ. Comput. Sci., 5(1), 21-27.

[2] Khan S., Dulloo A. B., Verma M. (2014), Systematic review of requirement elicitation techniques. Int. J. Inf. Comput. Technol., 4(2), 133-138.

[3] Razali F. A., Razali R. (2012), A practical guide to requirements elicitation techniques selection - An empirical study. Middle-East J. Sci. Res., 11(8), 9.

[4] Al Mrayat O., Norwawi N., Basir N. (2013), Requirements elicitation techniques: Comparative study. Ijrdet. Com., 1(3), 1-10.

[5] Tiwari S., Rathore S. S. (2017), A Methodology for the Selection of Requirement Elicitation Techniques.

[6] Pan Z., Park H., Baik J., Choi H. (2007), A six sigma framework for software process improvements and its implementation. 14th Asia-Pacific Softw. Eng. Conf., 1(3), 446-453.

[7] Nicolaescu S., Kifor C. V., Lobonţ L. (2015), Design for six sigma applied on software development projects from automotive industry. Acad. J. Manuf. Eng., 12(4), 76-83. 
[8] Pillai A. K. R., Pundir A. K., Ganapathy L. (2012), Implementing integrated lean six sigma for software development: A flexibility framework for managing the continuity: Change dichotomy. Glob. J. Flex. Syst. Manag., 13(2), 107-116.

[9] Pawar R. P. (2015), A comparative study of agile software development methodology and traditional waterfall model. IOSR J. Comput. Eng., pp. 1-8.

[10] Kumar M., Shukla M., Agarwal S. (2013), A hybrid approach of requirement engineering in agile software development. In: 2013 International Conference on Machine Intelligence and Research Advancement, pp. 515-519.

[11] Bormane L., Gržibovska J., Bērziša S., Grabis J. (2016), Impact of requirements elicitation processes on success of information system development projects. Inf. Technol. Manag. Sci., 19(1), 57-64.

[12] Tiwari S., Rathore S. S., Gupta A. (2012), Selecting requirement elicitation techniques for software projects. In: 2012 CSI Sixth International Conference on Software Engineering (CONSEG), pp. 1-10.

[13] Egas R. (2015), Requirements elicitation, which method in which situation? Open Univ. Netherlands, p. 70.

[14] Bennaceur A., et al. (2018), Requirements engineering to cite this version: HAL Id: hal-01758502.

[15] Nicoletti B. (2015), Optimizing innovation with the lean and digitize innovation process. Technol. Innov. Manag. Rev., March, pp. 29-38.

[16] Drohomeretski E., Gouvea Da Costa S. E., Pinheiro De Lima E., Garbuio P. A. D. R. (2014), Lean, six sigma and lean six sigma: An analysis based on operations strategy. Int. J. Prod. Res., 52(3), 804-824.

[17] Mirela A., Munteanu C. (2017), Comparative analysis between lean, six sigma and lean six sigma concepts. J. Manag. Econ., 2(1), 78-89.

[18] Antony J., Setijono D., Dahlgaard J. J. (2014), Total quality management \& business excellence lean six sigma and innovation - An exploratory study among UK organisations. 27(December), 37-41.

[19] Panat R., Dimitrova V., Selvy Selvamuniandy T., Ishiko K., Sun D. (2014), The application of lean six sigma to the configuration control in intel's manufacturing R\&D environment. Int. J. Lean Six Sigma, 5(4), 444-459.
[20] Reijns T. (2010), The advantages and limitations of lean six sigma in process (re)design. June, p. 32.

[21] Ben Ruben R., Vinodh S., Asokan P. (2017), Implementation of lean six sigma framework with environmental considerations in an Indian automotive component manufacturing firm: A case study. Prod. Plan. Control, 28(15), $1193-1211$.

[22] Swarnakar V., Vinodh S. (2016), Deploying lean six sigma framework in an automotive component manufacturing organization. Int. J. Lean Six Sigma, 7(3), 267-293.

[23] Tenera A., Pinto L. C. (2014), A Lean Six Sigma (LSS) project management improvement model. Procedia - Soc. Behav. Sci., 119, 912-920.

[24] ArunKumar G., Dillibabu R. (2016), Design and application of new quality improvement model: Kano lean six sigma for software maintenance project. Arab. J. Sci. Eng., 41(3), 997-1014.

[25] Girmanová L., Šolc M., Kliment J., Divoková A., Mikloš V. (2017), Application of six sigma using DMAIC methodology in the process of product quality control in metallurgical operation. Acta Technol. Agric., 20(4), 104-109.

[26] Almakadmeh M., Abran A., Supérieure É. D. T., Québec U. (2017), The ISBSG software project repository: An analysis from six sigma measurement perspective for software defect estimation. pp. 693-720.

[27] Alkinaidri A., Alsulami H. (2018), Improving healthcare referral system using lean six sigma. Am. J. Ind. Bus. Manag., 8(2), 193-206.

[28] Hassan M. K. (2013), Applying lean six sigma for waste reduction in a manufacturing environment. Am. J. Ind. Eng., 1(2), 28-35.

[29] Li L., He S. G., Qi E. S. (2009), On software requirement metrics based on six-sigma. In: 2008 IEEE Symposium on Advanced Management of Information for Globalized Enterprises, AMIGE 2008 - Proceedings, pp. 295-297.

[30] ur Rehman T., Khan M. N. A., Riaz N. (2013), Analysis of requirement engineering processes, tools/techniques and methodologies. Int. J. Inf. Technol. Comput. Sci., 5(3), 40-48.

[31] Mohamed D., Jintian Y. (2017), A Decision Making Aid Model for Project Management: A Strategic Decision Process. 